plifies the best of it, but he has some useful and pointed things to say on "grantsmanship" and how certain nonscientific talents may conduce to getting research support.

Though Dixon disclaimed any intention to write a "scholarly" work he is in fact very well read, intelligent and fair minded and that is the more important part of scholarship anyway. Though scientists come in for some pretty plain speaking, nothing is said that will shake their basic faith in scientific meliorism - the belief that the world has been and may yet be made a better place to live in as a result of scientific research.

$$
\text { P. B. Medawar }
$$

\section{Dedicated to Dirac}

Aspects of Quantum Theory. Edited by Abdus Salam and E. P. Wigner. Pp. xvi+268. (Cambridge University: London, November 1972.) £7.10; $\$ 23.50$.

THIs is not just one of the many Festschriften which are now following each other in quick succession as the pioneers of twentieth century physics inexorably reach their sixtieth or seventieth birthday. The editors of this volume, dedicated to Dirac, have spared no effort to make it, not only a fitting tribute to one of the greatest of these pioneers, but a significant contribution, of lasting value, to the history of the heroic period of quantum theory. After a complete bibliography of Dirac's publications, the book opens with three biographical articles. The last of these, by J. Mehra, manages with remarkable psychological insight and literary talent to give a true-to-life picture of Dirac's unique genius and lovable personality; the preceding reminiscences of Van Vleck are, in a lighter vein, quite entertaining and as revealing of the author's as of his hero's character as travellers out of the beaten track in the Rockies and elsewhere. Then comes a sequence of twelve more specialized articles, authoritatively treating of the great problems of quantum theory to which Dirac's name is attached; these contributions are not strictly historical, they offer original views of their eminent authors on the problems in question and their later developments. There would be little point in commenting on them all; each reader will find some of them more to his taste than others. Personally, I found extremely valuable Wigner's considerations on the time-energy uncertainty relation, and thoroughly enjoyed Laurent Schwartz's candid confession of initial scandal when he learned of the " $\delta$-function" and of frightened surprise when he much later saw what the physicists had managed to achieve by manipulations of "distributions"-without being "entitled" to do so by the mathematicians.

L. ROSENFELD

\section{Physics of Atoms}

Atomic and Nuclear Physics. By John Yarwood. Pp. 608. (University Tutorial Press: London, 1973.) £3.90. IN recent years it has become the fashion in many university physics courses to introduce atomic and nuclear physics with a large dose of quantum mechanics and in this way to instil some of the difficult theoretical concepts at an early state in an undergraduate's career. Such courses have a great attraction for those with strong mathematical leanings but of necessity the emphasis on theory has relegated the historical and experimental aspects of the subject very much to second place. It is, therefore, interesting to find this new book on atomic and nuclear physics which adopts the unfashionable approach with the emphasis on experiments and on the elementary principles underlying them. Tackling the subject in this way makes rather less demand on the mathematical ability of the reader and yet enables him to familiarize himself with many of the phenomena on the atomic and subatomic scale and to learn something of the techniques used in their study.

The first half of the book is concerned with atomic physics which is approached through mass spectroscopy, atomic structure and the elements of wavemechanics: it also includes chapters on $X$ radiation and atomic magnetism. A very considerable amount of material is covered and the accounts of experiments contain valuable detail which is so often omitted in textbooks. It is perhaps surprising that little mention is made of the photoelectric effect which historically played such an important role in the development of ideas on the particle nature of light, and the sole reference is to the part it plays in the attenuation of an $\mathrm{X}$ ray beam. The second and larger half of the book is devoted to nuclear physics which is introduced through natural radioactivity and the properties of radiations. It then proceeds through chapters on particle accelerators, detectors and nuclear fission to nuclear structure, reactions and elementary particles. The strongly experimental flavour is reffected in the considerable space devoted to neutron physics and its application to reactors. Again the coverage is broad and most of the important phenomena of nuclear physics are included and well described.

Although there are several significant errors of physics in the book, this is perhaps hardly surprising in a work which is so wide-ranging. The topics are treated concisely and readably and a wealth of material is contained in this relatively inexpensive book. It is certain that if it were on the shelves of a library it would be used by undergraduates because of the clear and simple way in which the information is laid out. As a course textbook, however, it is likely to be of most value where quantum mechanics plays little part in the course.

M. A. GRACE

\section{African Gastropods}

Sea Shells of Southern Africa-Gastro. pods. By Brian Kensley. Pp. 225. (Maskew Miller: Cape Town, in collaboration with the South African Museum, 1973.)

SouTH AFRICAN shores stretch for a distance of well over 2,000 miles and include four climatic zones with the Benguela Current extending cold conditions well up the east coast and the Mocambique and Agulhas Currents on the west bringing semi-tropical conditions as far south as Durban and warming the southern shores. The diversity of the shore populations was fully described in pre-war surveys made by the late Professor T. A. Stephenson.

Although a few shells from South Africa were named by Linnaeus and Lamarck, systematic collection did not begin until the middie of the last century largely by British and United States survey vessels. These were later extended by the Challenger and the Valdivia which trawled and dredged to some depth. Collection by local trawlers had begun by the end of the century.

British conchologists, notably G. B. Sowerby (the third), E. A. Smith and J. R. le B. Tomlin, played a notable part in establishing on a sound basis the taxonomy of South African marine Mollusca. This was followed by the impressive contributions between 1951 and 1964 of K. H. Barnard of the South African Museum.

There have been unfortunate episodes in South African conchology, notably the entirely uncritical Marine Shells of Port Alfred, South Africa published by W. H. Turton in 1932. The need for an authoritative and comprehensive account of this most interestingly diverse fauna has long been clear. This task has now been assumed by Brian Kensley of the South African Museum in a volume devoted to gastropods. After an informative introduction, full scope is given to the work of a team of three artists who illustrate, often in colour and invariably with great clarity, all the 900 species.

While I would have welcomed infor. mation about habits and habitat, certainty about species is the first essential and both professional and amateur malacologists will welcome this book and look forward to its successor covering the bivalves and other marine molluscs. This is a South African Museum Publication but strangely carries no price nor any indication of the locality of the shore scene depicted on the end papers. C. M. YONGE 